\title{
A IMPORTÂNCIA DA RECEPÇÃO DE CALOUROS E O IMPACTO NA FORMAÇÃO ACADÊMICA. O CASO DE SUCESSO DA ESCOLA DE ENGENHARIA DA UFMG: O ENGENHARIA RECEBE
}

\author{
Ana Paula Pereira Theobald - anaptheobald@gmail.com \\ Joanna Pinheiro Rodrigues - joannaprodrigues@gmail.com \\ Karine Fernandes Brandão - karinebrandao8@gmail.com \\ Magno Corrêa de Morais Costa - magnocmc3@gmail.com \\ Rayssa Sarah de Oliveira Guimarães - rayssasog@gmail.com \\ Alessandro Fernandes Moreira - moreira@cpdee.ufmg.br \\ Universidade Federal de Minas Gerais \\ Escola de Engenharia \\ Av. Presidente Antônio Carlos, 6627, Campus Pampulha \\ 31270-010 - Belo Horizonte - Minas Gerais
}

Resumo: Nos últimos anos, várias medidas têm sido tomadas para transformar o ensino de engenharia no Brasil, adaptando-o para uma estrutura que permita uma participação mais efetiva do aluno no processo de ensino-aprendizagem, bem como uma melhor relação entre discentes, docentes e instituição. Nesse sentido, vários estudos têm sido realizados para entender as "dores dos estudantes" e, assim, as causas dos altos índices de evasão e tempo de integralização dos cursos de engenharia. O acolhimento no ano de ingresso tem se mostrado com grande potencial para mitigar as dificuldades de integração do aluno e, consequentemente, impactar em toda sua trajetória acadêmica e influenciar fortemente na decisão de permanecer ou não na Graduação. Este trabalho apresenta o "Engenharia Recebe", evento de recepção de calouros da Escola de Engenharia da UFMG realizado por alunos que vêm ocorrendo desde 2012. Serão apresentados a estrutura e os conceitos que fundamentam este evento de recepção. O Engenharia Recebe vem promovendo a integração social, espacial e acadêmica do aluno ao longo dos semestres, e, assim, incentivando o estudante, desde seu ingresso na instituição, a criar laços com a Universidade e com a Escola de Engenharia, tornando-se uma atividade fundamental para sua formação em Engenharia.

Palavras-chave: Recepção de Calouros. Acolhimento e Pertencimento. Inovação no Ensino de Engenharia.

\section{INTRODUÇÃO}

A partir da década de 1980, a educação no país entrou em um processo de transformação de suas diretrizes e métodos, processo guiado principalmente pelos trabalhos promissores e vanguardistas de Paulo Freire. A transformação no ensino de engenharia, por sua vez, tem seu marco inicial com a promulgação da Lei de Diretrizes e Bases da Educação em 1996, que trouxe oportunas inovações ao Ensino Superior, entre elas a flexibilização curricular, de 


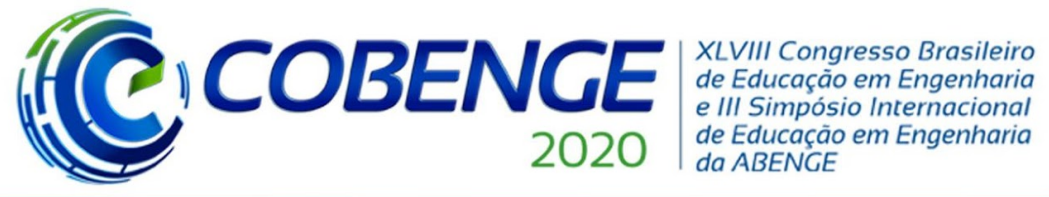

"Os desafios para formar hoje o engenheiro do amanhã"

grande importância para Engenharia que é uma profissão das mais dinâmicas (LDB, 1996). A partir desta data, o processo de transformação no ensino de engenharia tornou-se um trabalho coletivo marcado por grandes movimentos e pela realização de projetos estruturantes, tais como o Programa de Desenvolvimento das Engenharias (PRODENGE). O PRODENGE incorporou contribuições de uma parcela expressiva da comunidade acadêmica, de institutos, universidades e centros de pesquisa e de entidades representativas da engenharia nacional, dentre elas a Associação Brasileira de Ensino de Engenharia (ABENGE). Várias reuniões e seminários foram realizados, cujas discussões se pautaram em questões tais como a formação acadêmica, a atualização da engenharia, a sua integração nas atividades produtivas e de interesse social, bem como a atualização da engenharia e dos engenheiros no Brasil e no mundo. Toda esta mobilização em prol da transformação do ensino de engenharia culminou com a criação de dois subprogramas: Reengenharia do Ensino de Engenharia (REENGE) e Redes Cooperativas de Pesquisa (RECOPE) (LONGO, 2009).

O esforço do REENGE e do RECOPE culminou com o estabelecimento das Diretrizes Curriculares Nacionais (DCNs) para as Engenharias em 2002, que definiram os princípios, fundamentos, condições e procedimentos da formação de engenheiros para o desenvolvimento e avaliação dos projetos pedagógicos dos cursos de Graduação em Engenharia das instituições de ensino superior (IES) brasileiras (Res. CNE/CSE 11/2002). Estas diretrizes estabeleceram o perfil profissional do egresso, com formação generalista, humanista, crítica e reflexiva, capacitado a absorver e desenvolver novas tecnologias, estimulando a sua atuação crítica e criativa na identificação e resolução de problemas, considerando seus aspectos políticos, econômicos, sociais, ambientais e culturais, com visão ética e humanística, em atendimento às demandas da sociedade (CARVALHO; MOREIRA, 2009). A Resolução CNE/CSE 11/2002 tornou-se um outro marco para a transformação no ensino de engenharia, principalmente ao se considerar o novo perfil sensível e cooperativo do engenheiro, cuja finalidade é formar profissionais capazes de solucionar problemas complexos (CHANG, 2000).

A transformação no ensino de engenharia ganha novo marco em 2019, quando são instituídas as novas DCNs em Engenharia (Res. CNE/CSE 02/2019), um aprimoramento da Res. CNE/CSE 11/2002, especialmente na forma de elaboração dos projetos pedagógicos, que deverão ser estruturados por competências e propondo inovações na metodologia de ensino e nos processos de avaliação. Essa aprimoramento é fundamental para definição de novos perfis de egressos, bem como a criação de novas profissões em Engenharia.

Entretanto, dois problemas recorrentes ainda persistem, tanto na estrutura de ensino em engenharia nas IES quanto na relação que os alunos têm com a própria universidade: os altos índices de evasão e o extenso tempo de integralização (FILHO, 2017; INEP/MEC, 2018). As mudanças nos mecanismos educacionais e a transformação do ensino de engenharia têm sido incontestáveis, porém as IES de Engenharia ainda carecem de alterações importantes, em especial no que tange a amorosidade e o diálogo como elementos indispensáveis para o processo educativo. Segundo Freire (1992), "o diálogo é o encontro amoroso dos homens que, mediatizados pelo mundo, o "pronunciam", isto é, o transformam, e, transformando-o, o humanizam para a humanização de todos".

Do ponto de vista teórico, para explicar os problemas relacionados à retenção de alunos, uma referência é o trabalho de Tinto (1975), que afirma que a evasão se dá devido a falhas na integração acadêmica e social do aluno ao novo ambiente da universidade. Recentemente, 
Tinto (2017) afirmou que as IES teriam um papel primordial na promoção do "sentimento de pertencimento" nos alunos, uma das dimensões da motivação, sendo responsável por promover experiências para que eles vejam a instituição como acolhedora e um local de apoio, o que impactaria fortemente a decisão de permanência ou evasão no futuro. Além disso, ele também argumenta a necessidade de isso ser feito no ano de ingresso do aluno.

Outros estudos corroboram com a visão de que a promoção do sentimento de pertencimento e da motivação são essenciais para a satisfação do aluno com a universidade. Carneiro (2017), em um estudo realizado com mais de 3.000 alunos da Unicamp, conseguiu relacionar baixos níveis de evasão, maior regularização na integralização do curso e maior coeficiente de rendimento com altos níveis de engajamento. Estes níveis que, por sua vez, foram alcançados pelos alunos que mostraram mais se sentir parte da Universidade e mais satisfeitos com ela. Nesse sentido, mais satisfação com a instituição se relaciona diretamente com menor evasão, segundo a teoria de Tinto (1975).

Além dos motivos citados, uma gama de causas psicossociais podem também levar estudantes a desistir de completar sua graduação. Os principais motivos indicados na literatura para a evasão são: ensinos básico e médio de baixa qualidade; relações sociais insatisfatórias estabelecidas na universidade, tanto com colegas quanto com professores e funcionários; baixa oferta de atividades complementares; vulnerabilidade socioeconômica, que leva à necessidade de trabalhar ou a depender financeiramente para bancar os estudos; e características sociodemográficas familiares, como longos trajetos entre o domicílio e a instituição, ou ser da primeira geração a estar cursando o ensino superior (AMBIEL, 2015). Neste contexto, torna-se extremamente necessária a criação de ações e projetos de ensino nas IES a fim de realizar um efetivo acolhimento dos estudantes ingressantes.

A Escola de Engenharia da UFMG (EEUFMG), desde 2012, vem propondo novos rumos na formação de seus estudantes. Com o intuito de prover um ensino de excelência e uma referência na educação, a EEUFMG visa melhorias em sua estrutura organizacional e didática, fortalecendo as atividades complementares nos currículos, fundamentais para a formação pessoal e profissional de seus alunos. Foi neste contexto que foi criado o Programa de Inovação para Educação em Engenharia (Programa ENG200), que explora e dá mais alcance às iniciativas de sucesso que já existem na própria Escola e propõe melhorias em diversos aspectos, tanto curriculares quanto estruturais, para estimular a formação de profissionais mais alinhados às premissas do Engenheiro do Século XXI (MOREIRA, 2013). Dentre as várias ações e projetos desenvolvidos pelo Programa ENG200, destaca-se o "Engenharia Recebe". Realizado semestralmente desde 2012, este projeto tem como objetivo recepcionar os calouros de Engenharia, promovendo sua integração com o ambiente e com a comunidade e, assim, motivando-o desde o início de sua trajetória na EEUFMG.

Este trabalho apresenta o projeto "Engenharia Recebe", desde sua criação até a realização da última edição, no primeiro semestre de 2020, destacando, ainda, a relevância das atividades previstas em seu cronograma.

\section{O HISTÓRICO DO ENGENHARIA RECEBE}

O Engenharia Recebe surgiu após uma série de missões de trabalho realizadas por uma equipe da EEUFMG no Olin College (Olin), Boston/MA, e na Escola de Engenharia da 


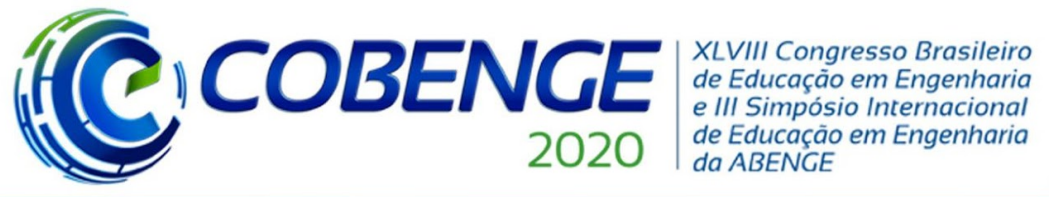

"Os desafios para formar hoje o engenheiro do amanhã"

University of Illinois at Urbana-Champaign (UIUC), Urbana-Champaign/IL. Em uma destas missões, a equipe da EEUFMG teve a oportunidade de conhecer o projeto intitulado iLaunch na UIUC. O projeto iLaunch é um um evento de recepção para os estudantes ingressantes, com o objetivo de incentivar, motivar e orientar sua jornada acadêmica. Foi neste contexto que a EEUFMG percebeu que muito poderia ser agregado à sua recepção institucional de calouros e criou o Engenharia Recebe no primeiro semestre de 2012.

Desde sua primeira edição em 2012, o Engenharia Recebe carrega em sua essência o ideal de acolhimento e amorosidade da instituição, dos professores e técnicos-administrativos e dos alunos veteranos, para com os ingressantes (FREIRE, 1992). Uma característica fundamental que marca o Engenharia Recebe é o protagonismo estudantil, uma vez que cada edição é idealizada e executada por alunos, com o apoio dos coordenadores dos cursos de Graduação e da Direção da EEUFMG. Tal característica faz com que as atividades propostas sejam ainda mais efetivas, pois é necessário que as ações de acolhimento sejam pensadas também com os olhares dos alunos, tornando-as, assim, mais convidativas. A recepção acontece sempre nas primeiras semanas de aula, pois o objetivo é fazer com que, desde o primeiro contato com a universidade, o aluno já se sinta acolhido, uma vez que são exatamente esses primeiros momentos que moldam sua experiência acadêmica e são decisivos para sua permanência no curso (TINTO, 2017). Em sua primeira edição, o Engenharia Recebe contou com a participação de representantes de organizações estudantis como Grêmios, Diretório Acadêmico da EEUFMG, Equipes de Competição e Empresas Juniores. A programação consistiu em uma série de atividades para apresentar a Escola de Engenharia ao aluno, com visitas guiadas, conversas com veteranos, além da cerimônia de abertura e da entrega de brindes. A cada edição subsequente, o evento foi amadurecendo e se modificando, de forma a acompanhar as novas demandas dos estudantes, calouros ou veteranos e, dessa forma, configurando uma dinamicidade e adaptabilidade ao evento. A partir de 2013, surgiram atividades mais voltadas para a responsabilidade social, além de realização de encontros para a integração dos estudantes. Como o evento vinha se tornando bastante tradicional no ambiente, outras entidades estudantis vinculadas à EEUFMG, antigas e recém-criadas, começaram a abraçá-lo, como, por exemplo, a Associação Atlética da Escola de Engenharia (AAEE) e a Charanga, com atividades em prol do incentivo à prática esportiva e cultural.

Com o passar dos semestres, novas atividades surgiram, como festivais de comidas, palestras e oficinas temáticas, as quais abordavam temas como gestão de tempo, saúde mental, intercâmbio, normas acadêmicas e demais assuntos demandados pelos alunos. É importante destacar que cada versão do Engenharia Recebe é única, uma vez que é sempre pensada e desenvolvida para e pelos diferentes perfis dos alunos que vão surgindo ao longo dos anos. A partir de 2017, o projeto recruta voluntários para organização do evento, ampliando e diversificando, assim, os perfis dos estudantes na organização. Ainda neste mesmo ano, uma das atividades mais integradoras e acolhedoras foi iniciada: o Apadrinhamento, no qual cada calouro recebe um padrinho ou madrinha, que irá ajudá-lo no processo de adaptação à instituição. A última edição do Engenharia Recebe, realizada no primeiro semestre de 2020, segue com a mesma essência das anteriores, porém foi pensada para despertar ainda mais o sentimento de acolhimento e integração dos ingressantes, de uma forma leve e descontraída. A próxima sessão apresenta as atividades desta última edição. 


\section{O ENGENHARIA RECEBE DO PRIMEIRO SEMESTRE LETIVO DE 2020}

Analisando as avaliações dos eventos de 2017 a 2020, ficou evidente a satisfação dos participantes pelo Engenharia Recebe. Nesse período de tempo, a média de aprovação do evento foi de $86 \%$. Adicionalmente, $87,8 \%$ dos que responderam os questionários de avaliação consideraram como excelente ou boa a divulgação, 92,2\% avaliaram como excelente ou bom o conteúdo apresentado e 91,1\% avaliaram como excelente ou boa a organização. A Tabela 1 apresenta a programação da edição 2020/1 do Engenharia Recebe, cujas atividades são detalhadas a seguir.

Tabela 1 - Programação do Engenharia Recebe de 2020/1

\begin{tabular}{c|c|c}
\hline HORÁRIO & DIA 1 & DIA 2 \\
\hline $11 \mathrm{~h} 00-12 \mathrm{~h} 00$ & Apresentação & Apadrinhamento \\
\hline $12 \mathrm{~h} 00-13 \mathrm{~h} 00$ & Almoço com veteranos & \multirow{2}{*}{-- } \\
\hline $13 \mathrm{~h} 00-15 \mathrm{~h} 00$ & Gincana & \multirow{2}{*}{ Visita } \\
\hline $15 \mathrm{~h} 00-16 \mathrm{~h} 00$ & Piquenique Solidário & \multirow{2}{*}{$\begin{array}{c}\text { Conversa com } \\
\text { Veteranos }\end{array}$} \\
\hline $16 \mathrm{~h} 00-17 \mathrm{~h} 00$ & Desafio de Engenharia & $\begin{array}{c}\text { Cheerleading } \\
17 \mathrm{~h} 00-18 \mathrm{~h} 00\end{array}$ \\
\hline $18 \mathrm{~h} 00-19 \mathrm{~h} 00$ & Apresentação Bateria Engrenada e Grifo & Palestra Institucional \\
\hline
\end{tabular}

Fonte: Organização Engenharia Recebe 2020/1 (Programa ENG200)

Apresentação - Na Apresentação, cerca de 35\% dos calouros foram reunidos no hall principal da EEUFMG. Esse número, embora não pareça alto, comparado com as últimas edições e em termos absolutos, demonstra a dimensão do evento, que tem um público médio de 140 pessoas. Os voluntários da organização do Engenharia Recebe se apresentaram e falaram um pouco sobre sua trajetória na EEUFMG. Em seguida, os participantes foram divididos em grupos de aproximadamente 30 pessoas, sendo cada grupo acompanhado por um voluntário. Várias dinâmicas foram realizadas proporcionando uma primeira descontração e integração entre os calouros e dos calouros com os estudantes voluntários.

Almoço com Veteranos - Após a Apresentação, os calouros foram convidados a almoçar com os voluntários. Formaram-se três grupos, cada grupo com destino a um diferente restaurante da UFMG, a fim de se oferecer cardápios e preços diversificados e, assim, abranger múltiplos perfis de estudantes. O objetivo desta etapa foi, além de gerar ainda maior integração entre os alunos calouros e veteranos, permitir uma ambientação no campus da UFMG. Adicionalmente, a programação foi planejada de modo a se ter um evento contínuo, evitando a dispersão dos estudantes ao longo da programação. 
Gincana - Esta etapa foi organizada e executada pela Engenharia Solidária, uma iniciativa estudantil da EEUFMG. As dinâmicas contaram com aproximadamente 30\% do número total de calouros, evidenciando que, como planejado, não houve uma grande dispersão dos alunos após o almoço. Os calouros foram divididos em grupos e vários jogos foram realizados, contribuindo para uma integração ainda mais efetiva. Premiações foram ofertadas para motivar a integração, que consistia em um kit de canecas e tirantes. A premiação ocorreu na Palestra Institucional, última atividade do dia. O objetivo com a premiação foi incentivar que os calouros participassem da programação até o final do primeiro dia.

Piquenique Solidário - Após as dinâmicas de integração, foi oferecido um lanche para os alunos. Além de buscar descontração, o piquenique foi mais uma forma encontrada para manter a presença dos calouros nas demais atividades do Engenharia Recebe.

Desafio de Engenharia - Após as atividades de integração social, foi realizado o "Desafio de Engenharia", uma atividade ao mesmo tempo lúdica e acadêmica. Os calouros, divididos em grupos, receberam um conjunto de materiais como jornal, barbante, balões, entre outros, e um ovo. As equipes tiveram 30 minutos para desenvolver um projeto de "paraquedas" para o ovo, que seria jogado do terceiro andar do Bloco de Aulas da EEUFMG e não poderia quebrar. Nesse momento ainda havia cerca de $20 \%$ dos alunos, que corresponde a cerca de 100 pessoas. Um destaque foi perceber o nível de motivação e entusiasmo dos calouros nesta etapa, provavelmente por causa dos laços mais fortes proporcionados pelas dinâmicas de integração anteriores e pelo desafio de "fazer a engenharia acontecer" nesta etapa.

Apresentação da Bateria Engrenada e do Grifo Cheerleading - Uma das atividades mais esperadas e tradicionais da recepção de calouros da EEUFMG, são as apresentações da Bateria Engrenada, charanga da Associação Atlética da Escola de Engenharia, e a apresentação da Equipe de Cheerleaders. Sendo um momento de celebração de boas-vindas aos calouros e contando com a presença de estudantes veteranos, funcionários e professores na plateia, esse momento é uma forma da comunidade acadêmica integrar ainda mais os participantes. A apresentação aconteceu logo após todas as dinâmicas do dia e, pelo horário escolhido, os alunos ingressantes do noturno também puderam participar.

Palestra Institucional - Última atividade do primeiro dia de programação, a Palestra Institucional é a cerimônia oficial de recepção, que contou com a participação de cerca $30 \%$ dos calouros. Nesta etapa, a Direção da Unidade, membros da Administração da EEUFMG e os coordenadores dos cursos de Graduação realizam suas apresentações dando as boas-vindas aos calouros (Figura 1). A abertura ocorreu ao final do dia, pois assim foi possível contemplar a disponibilidade de horários dos alunos de todos os turnos. Ao final, foram entregues as premiações da gincana para a equipe vencedora (Figura 2).

Apadrinhamento - No início da programação do segundo dia, ocorreu a atividade de apadrinhamento, quando os calouros puderam conhecer seus/suas respectivos/as padrinhos e madrinhas. Nesta etapa, foram também planejadas dinâmicas para sua integração. A estratégia do apadrinhamento é realizada por intermédio de um formulário preenchido pelos calouros, 


\section{COBENGE CCOBENCE 2020 da ABENGE}

informando hobbies, gostos musicais, perfil de estudo, cidade e estado de origem dentre outras. Um formulário semelhante também é preenchido pelos estudantes veteranos voluntários para o apadrinhamento. Ambos os formulários são encaminhados para os grêmios estudantis de cada curso de Graduação, que, juntamente com os voluntários, ficaram responsáveis por formar o par perfeito para cada calouro, tendo como base a sua personalidade. Desta forma, o apadrinhamento se torna mais efetivo, já que, além de ajudar academicamente o ingressante e lhe apresentar a instituição, o aluno é apresentado a um veterano com quem compartilha interesses e vínculos de origem.

Visita - Nesta etapa, o objetivo foi apresentar os diversos blocos que compõem o complexo da EEUFMG (blocos de aula, Biblioteca, Laboratórios, colegiados de Graduação e de PósGraduação, Centro de Experimentação etc.). Esta etapa foi uma atividade rápida e, ao longo da sua realização, vários estudantes foram tirando dúvidas sobre a Graduação. Esse é um momento de grande relevância para promover a adaptação do aluno ao ambiente.

Conversa com veteranos - Esta atividade foi realizada no Diretório Acadêmico da EEUFMG, quando os alunos puderam tirar suas dúvidas sobre várias temáticas, como intercâmbios, formas de estudo e perfis de professores dentre outras. Por ser uma atividade mais descontraída e apenas com alunos, os calouros se sentiram mais à vontade para perguntar sobre incertezas e inseguranças da vida universitária.

Figura 1 - Palestra Institucional da edição 2020/1.

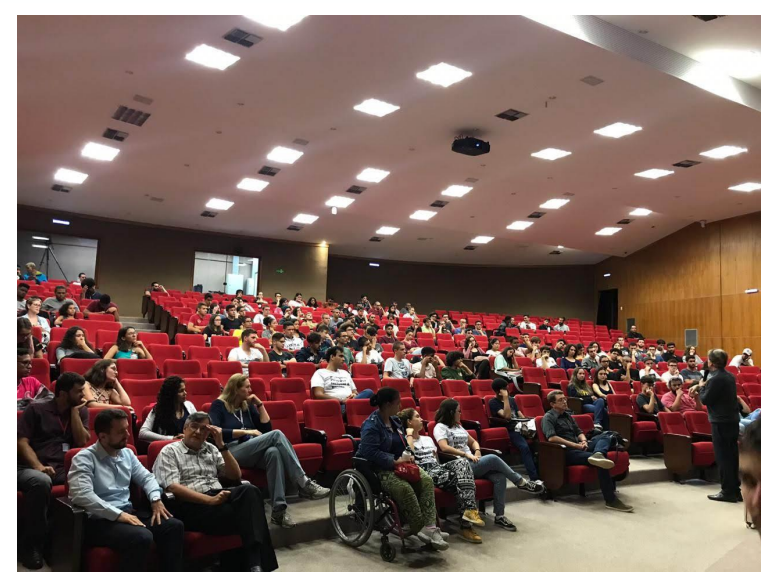

Fonte: Organização Engenharia Recebe 2020/1 (Programa ENG200)
Figura 2 - Equipe de calouros vencedora do Desafio na edição de 2020/1.

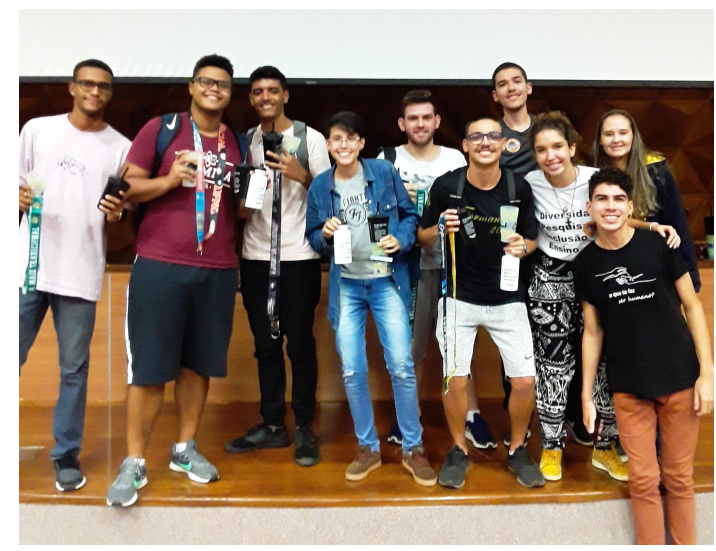

Fonte: Organização Engenharia Recebe 2020/1 (Programa ENG200)

Uma etapa decisiva para o sucesso do evento ocorreu antes dos dias de sua realização. Semanas antes, enquanto ocorria o registro e matrícula dos ingressantes na UFMG, membros da organização do Engenharia Recebe organizaram estandes para abordar os calouros logo em seu primeiro contato com a UFMG, apresentando o Programa ENG200, o evento Engenharia Recebe e as atividades programadas. Um questionário foi realizado para obter o contato e conhecer o perfil dos calouros. Ao longo dos dias do registro, a organização conseguiu obter 
261 respostas, sendo 505 o número total de calouros. Com estes dados, foi criado um grupo de WhatsApp para prover informações, tirar dúvidas e promover uma integração mais efetiva. Consequentemente, pôde-se estabelecer um canal simples de comunicação com os calouros, promovendo o acolhimento e a integração desde o início do semestre. A Figura 3 apresenta os brindes da edição do primeiro semestre de 2020, que consistiu em uma garrafa, um bottom e um porta cartão. Para os organizadores e parceiros, foi confeccionada uma camisa do evento.

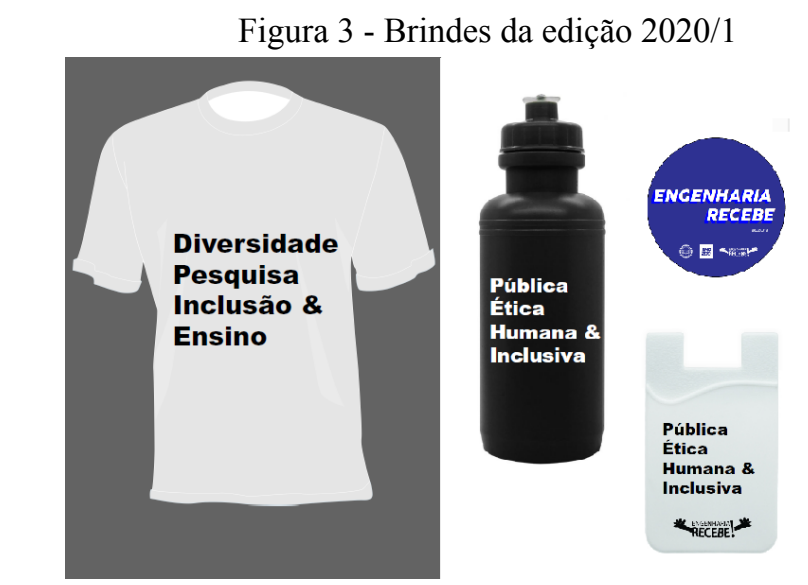

Fonte: Organização Engenharia Recebe 2020/1 (Programa ENG200)

\section{CONSIDERAÇÕES FINAIS}

O Engenharia Recebe, projeto desenvolvido no âmbito do Programa de Inovação para Educação em Engenharia (Programa ENG200), conta com uma programação lúdica e acolhedora que promove a integração dos calouros em diversos níveis, sejam eles sociais, acadêmicos ou espaciais, de forma a ampará-lo e deixá-lo mais à vontade em seu primeiro contato com a Escola de Engenharia e com a UFMG. O evento possui um caráter formal, sendo articulado com a recepção institucional da Universidade, porém com estrutura e programação flexíveis. Assim, o evento é moldado a cada semestre, seja por mudanças nos perfis dos próprios calouros, ou pelos aprendizados obtidos com as edições passadas. Consequentemente, os novos estudantes passam a criar um sentimento de pertencimento com a Escola de Engenharia e com a UFMG, o que impactará diretamente em sua motivação e experiência de formação acadêmica.

O Engenharia Recebe tem sido um sucesso ao longo de suas edições, mas há aspectos que precisam ser observados. Dentre eles, o número de calouros participantes, que oscilam de semestre a semestre e que normalmente é alto nas primeiras atividades e que vai diminuindo ao longo da programação. Um outro ponto importante é o acolhimento dos calouros dos cursos noturno, com poucas atividades para esse público. Um dos fatores que afetam o número de participantes é a concomitância do Engenharia Recebe com as atividades acadêmicas. Assim, é sempre uma dúvida se o evento deveria ocorrer em número reduzido de dias, ou ao longo das duas ou três primeiras semanas letivas. Porém, para que o Engenharia Recebe ganhe ainda mais espaço e prestígio, é necessário que se trabalhe para que os alunos da Escola de Engenharia enxerguem mais valor no evento e, assim, os calouros optem por atender, e sejam encorajados a isso pelos seus veteranos. 
Quando se trata de educação no ensino superior, a evasão e retenção são grandes problemas nas instituições, uma vez que é complexo e envolve questões da universidade, dos professores, da ambientação, além de fatores psicossociais. Acredita-se que o Engenharia Recebe vem contribuindo para minimizar estes problemas, uma vez que atua para fortalecer o pertencimento dos estudantes com a Universidade.

\section{REFERÊNCIAS}

AMBIEL, Rodolfo. Construção da Escala de Motivos para Evasão do Ensino Superior. Avaliação Psicológica, DOI: 14. 41-52. 10.15689/ap.2015.1401.05, 2015.

CARNEIRO, Ana M. Explorando o engajamento dos estudantes da graduação na universidade de pesquisa e os efeitos nos resultados da educação superior. In: $18^{\circ}$ Congresso Brasileiro de Sociologia, 2017, Brasília. Anais.

CARVALHO, Flávio; MOREIRA, Alessandro F. Diretrizes Curriculares para os Cursos de Engenharia: Um Aprimoramento. In: VI Encontro Nacional de Engenharia e Desenvolvimento Social, 2009, Campinas/SP. Anais.

CHANG, M. Engineers in the 21 st Century. IEEE Journal on Selected Topics in Quantum Electronics, v. 6, n. 6, p. 976-977, 2000.

CONSELHO NACIONAL DE EDUCAÇÃO. Resolução CNE/CSE 11/2002: Institui Diretrizes Curriculares Nacionais do Curso de Graduação em Engenharia. Diário Oficial da União, Brasília, 09 de abril de 2002. Seção 1, p. 32.

CONSELHO NACIONAL DE EDUCAÇÃO. Resolução CNE/CSE 02/2019: Institui Diretrizes Curriculares Nacionais do Curso de Graduação em Engenharia. Diário Oficial da União, Brasília, 09 de abril de 2002. 26de abrilde 2019, Seção 1, p. 43-44.

FILHO, Silva et al. A Evasão No Ensino Superior Brasileiro - Novos Dados. Disponível em: http://www.institutolobo.org.br/imagens/pdf/artigos/art_088.pdf. Acesso em: 02 mai. 2020 .

FREIRE, Paulo. Comunicação e Extensão. 10a edição, Rio de Janeiro: Paz e Terra, 1992.

INEP/MEC. Censo da Educação Superior 2018. Disponível em: http://portal.inep.gov.br/ censo-da-educacao-superior. Acesso em 02 mai. 2020.

LEI DE DIRETRIZES E BASES DA EDUCAÇÃO (LDB). Lei Federal no 9.394, 20 de dezembro de 1996.

LONGO, Wladimir P. e. O Programa de Desenvolvimento das Engenharias. Revista Brasileira de Inovação, Campinas, 3(2), p. 417-447, 2009. 
MOREIRA, Alessandro F. et al. Práticas Pedagógicas Integradoras e Tecnologias para o Ensino de Engenharia: Programa de Inovação na Educação em Engenharia. In: OLIVEIRA, Vanderli F. et al. DESAFIOS DA EDUCAÇÃO EM ENGENHARIA: Formação em Engenharia, Capacitação Docente, Experiências Metodológicas e Proposições. 1'. ed. Porto Alegre: Ed. Forma Diagramação, 2013, v. 1, p. 215-226.

TINTO, Vincent. Dropout From Higher Education: A Theoretical Synthesis of Recent Research. Review of Educational Research, v. 45, n. 1, p. 89-125, 1975.

TINTO, Vincent. Reflections on Student Persistence. Student Success, v. 8, n. 2, p. 1-8, 2017.

\title{
THE RELEVANCE OF THE FRESHMEN WELCOME RECEPTION AND ITS CONSEQUENCES IN THE ACADEMIC FORMATION. THE SUCCESS CASE OF THE SCHOOL OF ENGINEERING OF UFMG: THE ENGENHARIA RECEBE
}

\begin{abstract}
In the last twenty years, several projects have been taken towards to engineering education transformation in Brazil, looking for a new curriculum that allows more effective student participation in the teaching-learning process, as well as a better relationship between students, teachers and the institution. On this way, several studies have been carried out to understand the "students difficulties" and the causes of the high dropout rates and time spent on engineering graduation. Freshmen reception event has been demonstrated to have great potential to mitigate the social integration difficulties among the students and, consequently, to impact on his entire academic trajectory and strongly influence the decision to remain or not in your major program. In this context, this work presents the "Engenharia Recebe", the official freshmen reception event of the School of Engineering of UFMG, which is carried out by students for students, that have been taking place since 2012. Information about the main concepts behind its fundamentals and structure are presented. Engenharia Recebe has been promoting the student's social, spatial and academic integration over the years, and, therefore, encouraging the student, since entering the institution, to create links with the University and the School of Engineering, becoming a fundamental activity for his formation in Engineering.
\end{abstract}

Keywords: Freshmen Welcome Reception. Reception and Belonging. Engineering Education Innovation. 